\title{
Lethal dose and clinical signs of Aeromonas hydrophila in Arapaima gigas (Arapaimidae), the giant fish from Amazon
}

\author{
Marcia K.R. Dias ${ }^{\mathrm{a}}$, Luciana S. Sampaio ${ }^{\mathrm{b}}$, Aldo A. Proietti-Junior ${ }^{\mathrm{b}}$, Eliane T.O. Yoshioka ${ }^{\mathrm{a}, \mathrm{c}}$, \\ Dália P. Rodrigues ${ }^{\mathrm{d}}$, Anselmo F.R. Rodriguez ${ }^{\mathrm{e}}$, Ricardo A. Ribeiro ${ }^{\mathrm{e}}$, \\ Fernando S.E.D.V. Faria ${ }^{e}$, Rodrigo O.A. Ozório ${ }^{\mathrm{f}, \mathrm{g}}$, Marcos Tavares-Dias ${ }^{\mathrm{a}, \mathrm{c}, *}$ \\ a Programa de Pós-graduação em Biodiversidade Tropical, Universidade Federal do Amapá, Macapá (UNIFAP), AP, Brazil \\ ${ }^{\mathrm{b}}$ Laboratório de Microbiologia, Universidade Federal do Amapá (UNIFAP), Macapá, AP, Brazil, Brazil

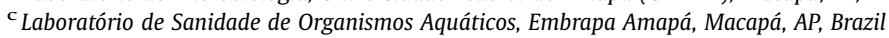 \\ d Laboratório de Enterobactérias, FIOCRUZ, Rio de Janeiro, RJ, Brazil \\ e Programa de Pós-graduação em Biotecnologia e Biodiversidade, Universidade Federal do Acre (UFAC), AC, Brazil \\ ${ }^{\mathrm{f}}$ Centro Interdisciplinar de Investigação Marinha e Ambiental (CIIMAR), Porto, Portugal \\ ' Instituto de Ciências Biomédicas Abel Salazar (ICBAS), Universidade do Porto, Porto, Portugal
}

\section{A R T I C L E IN F O}

\section{Article history:}

Received 10 December 2015

Received in revised form 31 March 2016

Accepted 1 April 2016

\section{Keywords:}

Aeromonas hydrophila

Bacteria

Infection

Tolerance limit

Pirarucu

\begin{abstract}
A B S T R A C T
Aeromonas hydrophila is causing substantial economic losses in world aquaculture. This study determined the tolerance limit $\left(\mathrm{LD}_{50-96 \mathrm{~h}}\right)$ of $A$. hydrophila in Arapaima gigas, and also investigated the clinical signs after intradermal inoculation. Arapaima gigas fingerlings were inoculated intraperitoneally with 0 (control), $1.0 \times 10^{5}, 1.0 \times 10^{6}, 1.0 \times 10^{7}, 1.0 \times 10^{9}$ and $1.0 \times 10^{10} \mathrm{CFU} / \mathrm{mL}$ of $A$. hydrophila for the determination of $\mathrm{LD}_{50-96 \mathrm{~h}}$, which was $1.8 \times 10^{8} \mathrm{CFU} / \mathrm{mL}$. In another trial with intradermal inoculation of $1.8 \times 10^{8} \mathrm{CFU} / \mathrm{mL}$ A. hydrophila, there was a $91.6 \%$ of mortality between 8 and $23 \mathrm{~h}$, and several clinical signs were found. As follows: depigmentation in the tegument, lesions in the tail and fins, loss of balance, reduction of respiratory movements, hemorrhagic foci, necrotic hemorrhages in the kidney, liver and swim bladder, splenomegaly, ascites in the abdominal cavity and hyperemia, enlargement of the gall bladder, among other clinical signs observed. The results showed that $A$. gigas has a relative tolerance to $A$. hydrophila when compared to other Neotropical fish species.
\end{abstract}

(c) 2016 Elsevier B.V. All rights reserved.

\section{Introduction}

Aquaculture strives to produce large quantities of fish in biological and economically efficient way, but infectious diseases are one of the major limiting factors for production (Plumb et al., 2011; Silva et al., 2012; Marinho et al., 2013) and productivity. Therefore, diseases prevention is of extreme importance to the aquaculture industry of fish as the Arapaima gigas Schinz, 1822 (pirarucu). This Arapaimidae species is known as the giant fish from Amazon because it can measure up to $3 \mathrm{~m}$ in length. This has good tolerance to the high densities of storage and its robustness in handling (Cavero et al., 2003; Araújo et al., 2009; Marinho et al., 2013). However, during the early stages of $A$. gigas culture, it encounter many problems with bacterial diseases which often cause high economic losses for fish farming due to high mortality rates.

\footnotetext{
* Corresponding author at: Rodovia Juscelino Kubitschek, km 5, 2600, 68903-419, Macapá, AP, Brazil.

E-mail address: marcos.tavares@embrapa.br (M. Tavares-Dias).
}

Aeromonas hydrophila is an aquatic bacterium that can be isolated in estuarine waters, marine and freshwater, as well as in the intestinal tract of farmed fishes (Lallier and Higgins, 1988; Aoki, 1999; Janda and Abbott, 2010). This pathogen causes ulcerations, haemorrhagic focus, epizootic ulcerative syndrome, and erosion of the fins in farmed and wild fish. Its pathogenicity is mediated by different extracellular proteins such as aerolysin, lipase, chitinase, amylase, gelatinase, hemolysins, enterotoxins in addition to type III secretion system (TTSS); a specialized protein, whose role is to export virulence factors directly into the host cells, subverting the normal functions of the host for the benefit of invasive bacteria. The ADP-ribosylating toxin that leads to the interruption of the NF$\mathrm{kB}$ pathway, cytoskeleton damage and apoptosis are characterized in A. hydrophila (Aoki, 1999; Janda and Abbott, 2010; Plumb et al., 2011; Carraschi et al., 2012; Doan, 2013; Silva et al., 2012; Song et al., 2014; Stratev and Vashin, 2014).

It has recognized that $A$. hydrophila is a pathogenic agent not only for fish, amphibians, reptiles, but also for different species of mammals including man (Lallier and Higgins, 1988; Aoki, 1999; Janda and Abbott, 2010; Plumb et al., 2011). In fishes, many 
infectious diseases display chronic characteristics that include clinical signs that persist for weeks, during which time the mortality rate increases gradually and the cumulative mortality can be high (Plumb et al., 2011).

The bacteriosis is dependent on the number of bacteria, whose concentration is variable according to the species infected and factors such as virulence, route of inoculation and temperature (Plumb et al., 2011; Carraschi et al., 2012; Song et al., 2014). Studies of experimental infection are necessary for each species, allowing the development of protocols for the prophylaxis and treatment that are more efficient against dangerous pathogen for fish farming. The objective of the current study was to determine the tolerance limit $\left(\mathrm{LD}_{50-96 \mathrm{~h}}\right)$ of A. hydrophila to A. gigas, and the clinical signs after intradermal inoculation of the lethal concentration, to be applied in challenge tests.

\section{Materials and methods}

\subsection{Fish and acclimatization}

The fingerlings of $A$. gigas $(38.8 \pm 7.1 \mathrm{~g}$ and $29.6 \pm 7.9 \mathrm{~cm}$ ) were purchased from a commercial fish farm and were acclimated in the Laboratory of Aquaculture and Fisheries, Embrapa Amapa, Macapá (Brazil) in tanks of $1000 \mathrm{~L}$ of water. During the nursery, fish were fed with extruded feed containing $45 \%$ crude protein (CP) and, subsequently with extruded ration containing $40 \% \mathrm{CP}$.

\section{2. hydrophila and preparation of the culture medium}

A. hydrophila (American Type Culture Collection 7966 (ATCC 7966) was obtained at the National Reference Laboratory for Bacterial Enteroinfections (LABENT) of the Oswaldo Cruz Institute (FIOCRUZ), Rio de Janeiro (Brazil), belonging to the Collection of Bacterial Enteropathogens and maintained in cryopreservation.

The liquid culture medium Brain Heart Infusion (BHI - Fluka Analytical - Sigma AldrichTM, St. Louis, MO, USA) was prepared according to the instructions of the manufacturer by dissolving $37 \mathrm{~g}$ in $1 \mathrm{~L}$ of distilled water. The sterilization was processed by autoclaving at $121^{\circ} \mathrm{C}$ for 15 min (Phoenix ${ }^{\circledR}$ AV 75, SP, Brazil). The GSP cultivation agar medium (GSP Agar - Fluka Analytical - Sigma AldrichTM, St. Louis, MO, USA) was prepared according to the manufacturer's instructions by dissolving $45 \mathrm{~g}$ in $1 \mathrm{~L}$ of distilled water and sterilized by autoclave at $121^{\circ} \mathrm{C}$ for $15 \mathrm{~min}$. After removal and cooling between 45 and $50^{\circ} \mathrm{C}, 100,000$ International Units of Penicillin G per liter (UI/L) were added followed by homogenization and distribution in $90 \mathrm{~mm}$ sterile disposable Petri dishes.

\subsection{Preparation of hydrophila suspensions}

Bacterial suspensions were prepared by transferring a heave containing three to five colonies of $A$. hydrophila isolated in Petri dishes containing the GSP agar medium after $24 \mathrm{~h}$ of cultivation at $35^{\circ} \mathrm{C}$ to Falcon tubes containing $10 \mathrm{~mL}$ of BHI broth and reincubated for $18 \mathrm{~h}$ in a bacteriological incubator (Olidef ${ }^{\mathbb{R}} \mathrm{CZ}$ ECB1 Linea, SP, Brazil).

After incubation of the bacterial suspensions with the culture, logarithmic growth phase was measured by turbidity caused by bacterial growth; densitometer Densichek ${ }^{\mathrm{TM}}$ (BioMerieux, Marcy l'Etoile, France) was designed to measure the optical density of a suspension of microorganisms. The values were processed in nephelometric units of McFarland and adjusted to the respective concentrations of the number of tubes from 0.5 to 7 of that scale. To obtain concentrations exceeding the reading capacity of Densichek $^{\mathrm{TM}}$, bacterial inocula were adjusted and subsequently, suspensions from $10 \mathrm{~mL}$ were centrifuged at $1000 \mathrm{~g}$ for five minutes for the formation of pellet with ten times concentration. Once standardized bacterial concentrations and, respected the interval of up to $15 \mathrm{~min}$ after adjustment, fish were inoculated with the bacterial suspension.

\subsection{Lethal dose $\left(L D_{50-96 h}\right)$ of hydrophila to A. gigas}

Ninety specimens of A. gigas ( $353 \pm 110 \mathrm{~g}$ and $39 \pm 27 \mathrm{~cm}$ ) were distributed in six tanks of $100 \mathrm{~L}$ ( $\mathrm{n}=15 \mathrm{fish} / \operatorname{tank}$ ), and maintained in fasting during the $96 \mathrm{~h}$ previously to the $\mathrm{LD}_{50}$ trial. Fish were inoculated intraperitoneally with $1.0 \mathrm{~mL}$ of $A$. hydrophila suspension with the following concentrations of the bacterium: $0 \mathrm{CFU} / \mathrm{mL}$ (control using $1.0 \mathrm{~mL}$ of $\mathrm{NaCl} 0.85 \%$ ), $3.0 \times 10^{5} \mathrm{CFU} / \mathrm{mL}, 3.0 \times 10^{6}$ $\mathrm{CFU} / \mathrm{mL}, 3.0 \times 10^{7} \mathrm{CFU} / \mathrm{mL}, 1.0 \times 10^{9} \mathrm{CFU} / \mathrm{mL}$ and $1.0 \times 10^{10} \mathrm{CFU} / \mathrm{mL}$. The $\mathrm{LD}_{50-96 \mathrm{~h}}$ was estimated using the Spearman-Karber method (Hamilton et al., 1977).

This study was conducted in accordance with the principles adopted by the Brazilian College of Animal Experimentation (COBEA) and was approved by the Ethics Committee on Animal use (CEUA/UFAC: 08/2014).

\subsection{Intradermal inoculation of hydrophila in A. gigas}

Fingerlings of $A$. gigas $(320 \pm 120 \mathrm{~g}$ and $38 \pm 28 \mathrm{~cm})$ were acclimated for three days in aquaria of $100 \mathrm{~L}$ of water and kept under constant aeration, for intradermal inoculation of $A$. hydrophila in the region of the caudal peduncle exactly on the lateral line. The bacterial suspension was adjusted to $1.0 \times 10^{8} \mathrm{CFU} / \mathrm{mL}$ and, once standardized as previously described, and observing the range for up to $15 \mathrm{~min}$ after adjustment, fishes were inoculated. Fishes were divided into two treatments, $0 \mathrm{CFU} / \mathrm{mL}$ (inoculated control with $0.5 \mathrm{~mL}$ of $\mathrm{NaCl}$ solution $0.85 \%$ ) and $0.5 \mathrm{~mL}$ of the bacterium suspension of $1.0 \times 10^{8} \mathrm{CFU} / \mathrm{mL}$ and three repetitions each, were inoculated with the bacterial suspension intradermal, to investigate for clinical signs of bacteriosis. The inoculation of fish in the control group preceded those of the group that received the inoculation of $A$. hydrophila to avoid possible cross-contamination. Observations were made of behavioral changes, morbidity and mortality of the fish after inoculation for a period of $24 \mathrm{~h}$.

\subsection{The water quality in the assays with hydrophila}

During the assays, the static water system and constant sandblasting was used. On a daily basis, a portion of the volume of water tanks and aquariums was changed. The levels of dissolved oxygen $(6.0 \pm 0.1)$, temperature $\left(27.6 \pm 0.7^{\circ} \mathrm{C}\right), \mathrm{pH}(7.2 \pm 0.8)$, were measured daily, using multi-parametric probe (Hanna, mod. HI $\left.96715^{\circledR}\right)$ and the levels of total ammonia $(4.9 \pm 2.9 \mathrm{mg} / \mathrm{L})$ and nitrite $(0.03 \pm 0.03 \mathrm{mg} / \mathrm{L})$ were measured using digital apparatus (Hanna, mod. HI 96715 ${ }^{\circledR}$ ).

\section{Results}

Mortality was not observed after $96 \mathrm{~h}$ of inoculation with $1.0 \times 10^{5}$ and $1.0 \times 10^{5} \mathrm{CFU} / \mathrm{mL}$ of $A$. hydrophila. However, first

Table 1

Mortality of Arapaima gigas during the $\mathrm{DL}_{50-96 \mathrm{~h}}$ of Aeromonas hydrophila.

\begin{tabular}{llllll}
\hline Pathogen concentration (UFC/mL) & $24 \mathrm{~h}$ & $48 \mathrm{~h}$ & $72 \mathrm{~h}$ & $96 \mathrm{~h}$ & $\%$ \\
\hline 0 & 0 & 0 & 0 & 0 & 0 \\
$1.0 \times 10^{5}$ & 0 & 0 & 0 & 0 & 0 \\
$1.0 \times 10^{6}$ & 0 & 1 & 0 & 0 & 6.6 \\
$1.0 \times 10^{7}$ & 0 & 3 & 0 & 0 & 20.0 \\
$1.0 \times 10^{9}$ & 12 & 0 & 0 & 0 & 80.0 \\
$1.0 \times 10^{10}$ & 13 & 0 & 0 & 0 & 86.0 \\
\hline
\end{tabular}


mortalities occurred in $46.6 \%$ of fish inoculated with $1.0 \times 10^{9}$ and in $73.3 \%$ of fish inoculated with $1.0 \times 10^{10} \mathrm{CFU} / \mathrm{mL}$ (Table 1 ). In the current rearing conditions, it was determined that for $A$. gigas the lethal dose $\left(\mathrm{LD}_{50-96 \mathrm{~h}}\right)$ of $A$. hydrophila was $1.8 \times 10^{8} \mathrm{CFU} / \mathrm{mL}$. After inoculation with $A$. hydrophila and the report of fish mortality, hemorrhagic signs were observed during necropsy, probably caused by septicemia.

After intradermal inoculation with $1.8 \times 10^{8} \mathrm{CFU} / \mathrm{mL}$ of $A$. hydrophila, there was $91.6 \%$ mortality between 8 and $23 \mathrm{~h}$. In addition, fish showed alterations in behavior, which was not observed in control animals. In the tegument of $A$. gigas, macroscopic lesions such as reddish edges were observed at site of inoculation with A. hydrophila, but these lesions varied in form, length and size. The depigmentation along the tegument and lesions in the tail and fins were observed under various sizes and shapes. Large prominent projections were observed in the inoculation site of $A$. hydrophila. These lesions were filled with transparent to slightly turbid liquid, and in some cases, a slight dripping of blood that invariably caused the detachment of the skin in areas adjacent to the inoculation site. Fish had anorexia, loss of balance with erratic movement, reduction of respiratory movements, abnormal coloration along the body with hemorrhagic foci, abrasion of the dorsal fin, irregular lesions that left the muscles exposed in ventral and anal-fin rays, necrotic hemorrhages of internal organs such as kidney, liver and its modified swim bladder and splenomegaly were the signs which preceded the death of the fish after intradermal inoculation with $A$. hydrophila, besides ascites containing mucosal yellowish fluid, deposition of bloody fluid in the abdominal cavity, hyperemia, increased gall bladder, abdominal cavity with the swollen wall of its modified swim bladder, small areas of bleeding in the liver (Fig. 1) and humidity were found along these internal organs. These changes were observed in those fish inoculated with A. hydrophila, but did not occur in control fish inoculated with sterile saline solution (Fig. 1A).

In the transverse cross section of the fish inoculated with $A$. hydrophila, it was observed that the muscles had reduced its consistency and an extensive hemorrhagic area in the region inoculated with the bacterium.

\section{Discussion}

In recent years, world aquaculture has grown rapidly in terms of production, but intensive and stressful rearing conditions makes farmed fish highly susceptible to different infectious diseases, which are now the most serious problem for the aquaculture industry, causing heavy economic losses. Consequently, the intensive aquaculture have increased both the occurrence and severity of infections by Aeromonas spp., emerging as one of the main causes of high mortality in rearing freshwater fish (Plumb et al., 2011; Silva et al., 2012; Doan, 2013; Song et al., 2014), due to increased environmental stress (Plumb et al., 2011). Thus, in the fish farm, monitoring of environmental quality is essential (Marinho et al., 2013; Doan, 2013). In the assay of inoculation with $A$. hydrophila in A. gigas, water quality remained constant and was within the limits considered suitable for Amazonian fish (Araújo et al., 2009; Marinho et al., 2013). However, in Carassius auratus inoculated with $A$. hydrophila the water temperature affected the structure of the cellular membrane of this bacterium, resulting in differences in the mortality of the fish (Rahman et al., 2011), influencing thus the survival rates of fish.

In diseased fish, the clinical signs of aeromoniosis caused by $A$. hydrophila indicate that this primary pathogen, presents great economic importance to the freshwater fish farming (Silva et al., 2012). Aeromonas spp. can attack the fin, tegument and abdominal cavity, and may be able to break the blood vessels, resulting in
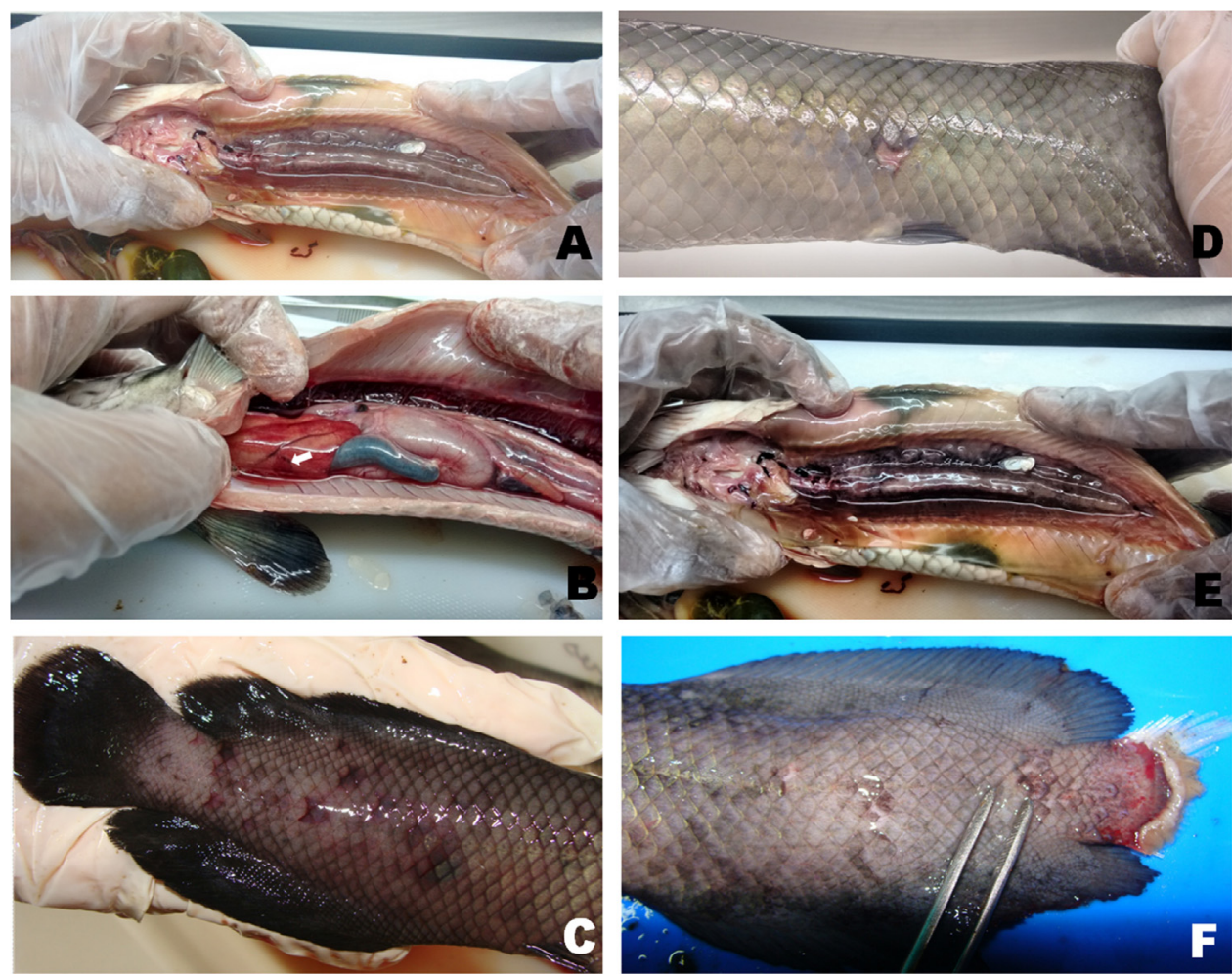

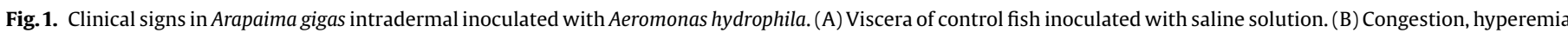

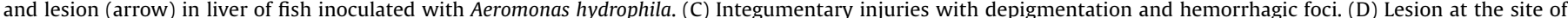

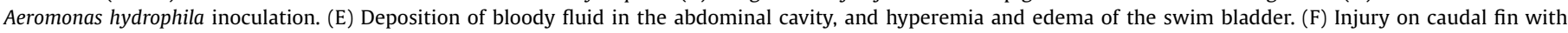
hemorrhagic foci. 
ulcerative lesions with a hemorrhagic appearance throughout the tegument (Silva et al., 2012; Doan, 2013).

In this study, A. gigas inoculated intraperitoneally with different concentrations of $A$. hydrophila only showed signs of hemorrhage in this cavity. The mortality of $A$. gigas occurred within $12 \mathrm{~h}$ after the beginning of inoculation. Toxins and extracellular enzymes, together with some structural characteristics of this bacterium, are considered important factors in the virulence of $A$. hydrophila (Aoki, 1999; Plumb et al., 2011; Silva et al., 2012; Stratev and Vashin, 2014), the bacterium that produces toxins (cholinesterase, aerolysin, $\alpha$ and $\beta$ hemolysins, enterotoxins, proteases, haemaglutinins, adhesins etc) are lethal to fish when in high quantity (Aoki, 1999; Boijink and Brandão, 2001; Silva et al., 2012).

The lethal concentration of $A$. hydrophila for $A$. gigas, was $1.8 \times 10^{8} \mathrm{CFU} / \mathrm{mL}$, similar concentration to that described for Pangasius bocourti, $2.2 \times 10^{8} \mathrm{CFU} / \mathrm{mL}$ (Doan, 2013). In contrast, it was lower when compared to reported lethal concentration for Brycon amazonicus, which was $6.6 \times 10^{11} \mathrm{CFU} / \mathrm{mL}$ and early mortality occurred only after $57 \mathrm{~h}$ of the beginning of intraperitoneal cavity inoculation (Oliveira et al., 2011). Studies performed in Labeo rohita showed that concentrations of $2.2 \times 10^{7}, 2.2 \times 10^{8}$ and $2.2 \times 10^{9} \mathrm{CFU} / \mathrm{mL}$ of $A$. hydrophila caused $100 \%$ mortality in $24 \mathrm{~h}$ after intraperitoneal inoculation, but early mortality occurred after $3 \mathrm{~h}$ from the beginning of the bacterial inoculation (Bharadwaj et al., 2013). However, as the mortality caused by A. hydrophila is also dependent on the concentration of bacteria, virulence factor (production of extracellular product) temperature, fish size and the type of bacteria strain used, the onset of clinical signs and pathogenicity vary between the fish species (Plumb et al., 2011; Carraschi et al., 2012; Silva et al., 2012; Doan, 2013; Song et al., 2014). Therefore, our results show that $A$. gigas exhibits high tolerance to A. hydrophila when compared to other Neotropical freshwater fish.

In A. gigas, loss of balance, erratic movement and reduction of slower respiratory movements were the signs preceding the death of the fish after intradermal inoculation of $A$. hydrophila. Such manifestations were also described for Rhamdia quelen intramuscularly inoculated with A. hydrophila (Boijink and Brandão, 2001), as well as for Oreochromis niloticus inoculated intraperitoneally (Eissa et al., 2009) and B. amazonicus (Oliveira et al., 2011), due to the presence of acetylcholinesterase, which exhibits narcotic effect by acting on the central nervous system of fish (Boijink and Brandão, 2001). However, due to the time period between the inoculation of $A$. gigas and its death, crateriform boils were not observed in these animals inoculated, maybe because of the small course of the pathological process. Many chronic infectious diseases in fish have characteristics which include maximum clinical signs that persist for weeks, during which the mortality rate increases gradually and cumulative mortality can be high (Aoki, 1999; Plumb et al., 2011; Song et al., 2014). In the postmortem inspection of fish in this study, when intradermal inoculated with $A$. hydrophila, there have been various clinical signs consistent with this bacteriosis, which have also been described for various fish species inoculated with varying concentrations of this same bacterium (Boijink and Brandão, 2001; Eissa et al., 2009; Carraschi et al., 2012; Silva et al., 2012; Oliveira et al., 2011; Doan, 2013; Stratev and Vashin, 2014). Therefore, all findings in this study provide important information not only on the pathogenesis of $A$. hydrophila, but also for the development of treatment strategies for the control of this bacteriosis.
In summary, although the infected fish with lower concentrations of $A$. hydrophila showed no clinical signs and mortality, in fish farming the drastic environmental changes, improper management and parasitic infections are relevant factors that may cause outbreaks of bacterial diseases. Therefore, additional studies should be conducted in the search for improvements in immunological resistance of $A$. gigas against the pathogenicity of $A$. hydrophila.

\section{Acknowledgements}

This study was supported by Brazilian Federal Agency for the Support and Evaluation of Graduate Education (CAPES), through the project Pro-Amazônia (\#230238.00754/2013-61) and the PhD grant to first author. This study was also supported by the National Council of Scientific and Technological Development (CNPq, Brazil) by productivity grants for M. Tavares-Dias.

\section{References}

Aoki, T., 1999. Motile aeromonads (Aeromonas hydrophila). In: Woo, P.T.K., Bruno, D. W. (Eds.), Fish Diseases and Disorders: Viral, Bacterial and Fungal Infections. CABI Publishing London, pp. 427-453.

Araújo, C.S.O., Gomes, A.L., Tavares-Dias, M., Andrade, S.M.S., Belém-Costa, A., Borges, J.T., Queiroz, M.N., Barbosa, M., 2009. Parasitic Infection in pirarucu fry, Arapaima gigas Schinz, 1822 (Arapaimatidae) kept in semi-intensive fish farm in central Amazon, Brazil. Vet. Arhiv. 79, 499-507.

Bharadwaj, A., Abraham, T.J., Joardar, S.N., 2013. Immune effector activities in challenged rohu, Labeo rohita after vaccinating with Aeromonas bacterin. Aquaculture 16, 392-395.

Boijink, C.L., Brandão, D.A., 2001. Inoculação bacteriana de Aeromonas hydrophila e a sobrevivência de juvenis e Jundiá, Rhamdia quelen (Teleostei: Pimelodidae). Ciênc. Rural 31, 503-507.

Carraschi, S.P., Cruz, C., Neto, J.G.M., Moraes, F.R., Rossi Júnior, O.D., Nader Neto, A. Bortoluzzi, N.L., 2012. Evaluation of experimental infection with Aeromonas hydrophila in pacu (Piaractus mesopotamicus) (Holmberg, 1887). Int. J. Fish. Aquac. 4, 81-84.

Cavero, B.A.S., Pereira-Filho, M., Roubach, R., Ituassú, D.R., Gandra, A.L., Crescêncio, R., 2003. Efeito da densidade de estocagem na homogeneidade do crescimento de juvenis de pirarucu em ambiente confinado. Pesq. Agropec. Brasil 38, 103107.

Doan, H.V., 2013. The LD50 of Asian catfish (Pangasius bocourti, Sauvage 1870) challenge to pathogen Aeromonas hydrophila FW52 strain. Pen. J. 75, 287-293.

Eissa, I.A.M., Badran, A.F., Abd-Elmoez, A.M., 2009. Dietary sodium alginate as an immunostimulant in cultured Oreochromis niloticus and its resistance against Aeromonas hydrophila. Suez Canal Vet. Med. J. 14, 19-32.

Hamilton, M.A., Russo, R.C., Thurston, R.V., 1977. Trimmed Spearman-karber method for estimating median lethal concentrations in toxicity bioassays. Environ. Sci. Technol. 11, 714-719.

Janda, J.M., Abbott, S.L., 2010. The genus Aeromonas, taxonomy, pathogenicity, and infection. Clin. Microbiol. Rev. 23, 35-73.

Lallier, R., Higgins, R., 1988. Biochemical and toxigenic characteristics of Aeromonas spp. isolated from diseased Mammals, moribund and healthy fish. Vet. Microbiol. 18, 63-71.

Marinho, R.G.B., Tavares-Dias, M., Dias-Grigório, M.K.R., Neves, L.R., Yoshioka, E.T.O., Boijink, C.L., Takemoto, R.M., 2013. Helminthes and protozoan of farmed pirarucu (Arapaima gigas) in eastern Amazon and host-parasite relationship. Arq. Bras. Med. Vet. Zoot. 65, 1192-1202.

Oliveira, S.R., Souza, R.T.Y.B., Brasil, E.M., Andrade, J.I.A., Nunes, E.S.S., Ono, E.A., Affonso, E.G., 2011. LD $_{50}$ of the bacteria Aeromonas hydrophila to matrinxã, Brycon amazonicus. Acta Amaz. 41, 321-326.

Plumb, J.A., Larry, A., Hanson, L.A., 2011. Health Maintenance and Principal Microbial Diseases of Cultured Fishes, 3th edition Blackwell Publishing Ltd., Iowa, pp. 492. Rahman, M.H., Suzuki, S., Kawai, K., 2011. The effect of temperature on Aeromonas hydrophila infection in goldfish Carassius auratus. J. Appl. Ichthyol. 17, 282-285.

Silva, B.C., Mouriño, J.L.P., Vieira, F.N., Jatobá, A., Seiffert, W.Q., Martins, M.L., 2012. Haemorrhagic septicaemia in the hybrid surubim (Pseudoplatystoma corruscans x Pseudoplatystoma fasciatum) caused by Aeromonas hydrophila. Aquacult. Res. 43, 908-916.

Song, X., Zhao, J., Bo, J., Liu, Z., Wu, K., Gong, C., 2014. Aeromonas hydrophila induces intestinal inflammation in grass carp (Ctenopharyngodon idella): an experimental model. Aquaculture 434, 171-178.

Stratev, D., Vashin, I., 2014. Aeromonas hydrophila sensitivity to disinfectants. J. Fish. Sci. 8, 324-330. 